\title{
Interactive comment on "Climate impacts on deglaciation and vegetation dynamics since the Last Glacial Maximum at Moossee (Switzerland)" by Fabian Rey et al.
}

\section{Anonymous Referee \#2}

Received and published: 22 December 2019

The paper by Rey et al investigate the response of vegetation and fire to climate change from the LGM in central Europe using high-resolution pollen and charcoal analysis on a lacustrine record in the Swiss plateau, Moossee. The manuscript is very well written and organized, with objectives clearly stated. The methods used are generally sound. The chronology is more than robust, with 62 radiocarbon dates on a $1400 \mathrm{~cm}$ long core. Eventually, the amount of pollen analysis is impressive, with 514 samples analyzed, mostly concentrated between 8000 and 3000 cal BP. To sum up, this ms is a valuable contribution to the topics of deglacial vegetation change and Holocene Human impact in central Europe and is suitable for publication in Climate of the Past providing the authors addresses the comments below.

Printer-friendly version

Discussion paper 
1. Title : the ms does not really investigate the impact of climate on deglaciation, except in the first paragraph of the discussion where extent and retreat of ice sheet is briefly discussed in reference to radiocarbon age from lacustrine record north and south of the Alps. Therefore, this seems to be a little off the main topic of the paper. I would advise to change the title to reflect the focus on vegetation and fire (that does not appear in the title's current form).

2. In such paper discussing post-LGM and HE1 vegetation dynamics it is quite surprising not to see any references to paleoecological records in the same area/latitude covering these time slices and beyond such as La Grande Pile, Les Echets or Bergsee Lake (Becker et al 2006 is not the most uptodate reference). Please add.

3. Paleodiversity analysis are interesting but are not really informative (only multimillenial patterns to the best) and are not much used in the discussion. I am wondering if it is really necessary to keep it in the paper?

4. Use of Sporormiella and link to megafauna. First, Sporomiella is expressed as \% of total pollen sum, which is somewhat problematic (eg. Baker et al 2013; Etienne \& Jouffroy Bapicot, 2014) . Indeed, fungus and pollen does not belong to the same ecological community and expressing Sporormiella in percentage of the total pollen sum can lead to flawed results: for instance, the relatively high levels between 19 and 15.2 ka BP can either be related to higher presence of Sporomiella or to fluctuations in total pollen sum, or to change in sediment accumulation rate. Moreover, the chronology of the record is robust enough to calculate concentrations and accumulation rate, as it has been done for charcoal, which is also made possible by the use of Lycopodium in pollen slides preparation. I then strongly recommend to express Sporormiella in accumulation rate (nb.cm-2.yr-1), as it is the only way for authors to evidence their claim of more abundant coprophilous fungi between 19 and $15.2 \mathrm{ka} \mathrm{BP}$ and its potential link with megafauna presence and then extinction. As currently presented, the data do not

Interactive comment
Printer-friendly version

Discussion paper 
support the interpretation. Second, the discussion about the link between continuous abundance (not evidenced in the current dataset) and the presence of Pleistocene megaherbivores is too affirmative in its current form (eg p10 I 363-365) and should be reformulated. Sporormiella is strictly coprophilous, and then megaherbivores are not the only explanation for potential high abundances. Moreover, with Sporormiella expressed ad \% the authors cannot state that the extinction of megaherbivores is "also evidenced by decreasing numbers [of] dung spores after 16000 cal. BP" (p10 I370$371)$, since we do not know if the numbers of spores is actually decreasing (\% are, which is different).

5. Main pollen diagram is described in the results section with a phase beginning at 19200 cal. BP. But Figure Figure 3 seems not to exhibit pollen data prior to 1880019000 cal. BP ? Please check \& correct.

Interactive comment on Clim. Past Discuss., https://doi.org/10.5194/cp-2019-121, 2019. 